\title{
ON THE STATUS, ORIGIN AND EVOLUTION OF HOTSPOTS OF BIODIVERSITY
}

\author{
P.T. Cherian
}

Southern Regional Station, Zoological Survey of India, 100 Santhome High Road,Chennai,Tamil Nadu 600028, India.

\begin{abstract}
Perceptions differ about the area encompassing and the species composition of hotspots of biodiversity which are emergencycare areas of global conservation. Zoogeographical locations of the eighteen hotspots recognized by Myers are given, a few others identified later are named and some deserving recognition are mentioned. Some factors which have contributed to the origin, richness and evolution of the biodiversity of hotspots is discussed.

\section{Introduction}

Hotspots of biodiversity which have evolved through the ages caught the imagination of man only in the last decade. Myers (1988) for the first time recognized them as emergency-care areas of global conservation that both contain large numbers of endemic species and are under extreme threat. To the 10 tropical rain-forest hotspots he identified globally in 1988, based on plant diversity, he added eight more, including four mediterranean-type ecosystems, in 1990. These 18 areas collectively occupy only half a percent of the earth's land surface. Yet they are exclusive home for one fifth of the flora ,and many species of fauna of the world. Conservation International slightly modified and expanded Myers' list to include areas overlooked in the original analysis (Conservation International, 1990a).
\end{abstract}

The major tropical wilderness area approach was developed simultaneously by Myers $(1988,1990)$ and Mittermeier (Conservation International, 1990b). While the major habitats of hotspots have often been highly fragmented and greatly reduced to usually less than 25 per cent of their original pristine cover, the major tropical wilderness areas are still largely intact, retaining more than 75 per cent of the original vegetation. The latter also have low human population density ( $<5$ people $/ \mathrm{km})$.

Each of these hotspots covers very large areas. Thus one of the largest, the lower slopes of Himalaya, though now down by two-thirds its original forest cover, initially covered roughly $3,40,000$ sq. km. of dense forests. Even the smallest, New Caledonia, is still left with 1500 sq.km. of undisturbed forests (Wilson, 1992).

Received 19 June 1999;

Accepted 4 February 2000
Scattered across local mountains, ridges, valleys, and islands and extending from a few to several square kilometers, often within the hotspots, are areas of species concentration which Myers (1990) called the 'hottest of the hotspots'.

\section{Hot specks}

From the conservation. angle, Cherian (1996) designated hotspecks which are miniscule areas of species concentration, varying in size from five to rarely a few hundreds or more square meters falling within or far outside todays recognized hotspots where species-packing of diverse groups, including many endemics is found. Relative to the size of the area covered, these have tremendous value in conservation because much can be saved expending too little time and resources by protecting such areas. They should be set aside as inviolate areas. A few such areas have been named but many more may become known as more niches are thoroughly explored (Cherian,1996).

\section{Differing perceptions about the area and species composition of Hotspots}

As mentioned earlier, hotspots were justifiably conceived by Myers as very large areas extending from a few hundreds to thousands of square kilometers. Even his 'hottest of the hotspots' encompass a few to several square kilometers. Besides, they are havens of endemicity of diverse groups. Thus the floral endemicity may be as high as 80 per cent in Madagascar where all the lemurs and two-thirds of the chameleons of the world are seen, besides other reptiles and many amphibians, 90 percent of which are endemics (Wilson, 1992).

Unrelated to the gradual shrinking in the original forest cover of the 18 hotspots, there has been a perceptable change in the conception of some scientists about the extent of area a hotspot covers or its species composition. Thus Vogel indentified "hotspots" of biodiversity, sometimes only 20 sq.km. across in southern Europe (Copley, 1998).

According to him these hotspots served as safe havens for plant species during glaciation. Based on his studies of mostly Asplenium rock ferns across Europe, he identified 15 hotspots in Iberian Peninsula, Italy and the Balkans where more species of this genus were found than in the rest of Europe. According 
to Vogel these glacial refuges, which are "Noah's Ark" of European biodiversity should be protected as long-term havens of biodiversity (Copley, 1998).

Many wildlife sanctuaries and national parks recognized today individually encompass larger areas harbouring more diverse habitats, ecosystems and masses of rare and endemic species than any of the 15 hotspots recognized by Vogel. There are many such glacial refuges the world over where some species survive. Such centres may at best deserve the status of sanctuaries or national parks. By assigning the status of hotspots to small areas harbouring limited number of selected groups of organisms, one dilutes the usefulness of these well known terms as giant centres of global biodiversity conservation.

A reassessment of the biodiversity hotspots approach has been underway since 1996. Mittermeier et al. (1998), based on plant endemism and degree of threat, identified additional hotspot areas each with one-half per cent or more of total global plant diversity - a minimum of 1350 plants - represented as endemics. Based on this method, 24 high priority terrestrial hotspots were identified. Of these nine were adopted without change from Myer's list. Of the rest, seven were based on a modification (by addition of areas or combination) of those recognized by Myer. To these 16 were added, eight new ones namely, Tropical Andes, Mediterranean Basin, Mesoamerican forests, Caribbean islands, Polynesia/Micronesia, Succulent Karoo, New Zealand and Wallacea.

This new version of analysis includes a wider variety of terrestrial biomes with exclusively tropical rainforests accounting for only 37.5 per cent of the total. The remaining natural vegetation in these 24 hotspots covers only about two per cent of the land surface. Yet they are home for 45.9 per cent of all plant diversity represented as endemics. Conservatively these 24 hotspots harbour 50 per cent of all terrestrial biodiversity in only about two per cent of the land surface of the earth (Mittermeier, 1998). These are presumed to be home for at least 75 per cent of terrestrial species belonging to the Critically Endangered, Endangered and Vulnerable categories defined by IUCN (Groombridge \& Baille, 1996).

No list of hotspots of biodiversity can be all comprehensive. There are other candidates among forested regions like the rain forests of Liberia, Queensland and Hawaii as also entirely different habitats like the great lakes of East Africa, the river drainage systems from Tennessee to Ganges, the Baltic and Aral seas and a myriad of isolated tracts of deciduous forest grasslands, deserts and coral reefs (Wilson, 1992). Additions to the list of the hotspots should be made based on information having relatively comparable significance in conservation.

If one compares the most critical of WWF's global 200 ecoregions (Olson \& Dinerstein, 1997), the important endemic bird areas of Birdlife International (Statterfield et al., 1998) and the WWF/ IUCN centres of plant diversity (WWF/IUCN, 1994; 1995; 1997) with the hotspots recognized today, the same regions usually rise to the top. Hence the original message of Myers' hotspots analysis echoes loud and clear -- a high percentage of global terrestrial diversity can be protected in a small portion of earths' land surface. Therefore efforts at conservation should be centered heavily, though not exclusively, on these areas.

\section{Location of Hotspots}

In spite of major and minor declines along the way, the trend in biodiversity has been consistently upward. Global biodiversity has reached its Cenozoic pinnacle first by the creation of aerobic environment and second by the fragmentation of land masses. An analysis of the locations of the hotspots reveals that most of them are either located along areas where the earth's plates meet today or had met in the past. As for the rest, though most of them today are far removed from the edges of the plates, it is possible to trace their proximity to the points of contact with other plates as also in most cases their continuity with other hotspots in the geological past.

On the basis of an evaluation of the trend of evolution and biodiversity of the 18 hotspots (Fig. 1) recognized by Myers and the 24 by Mittermeier et al., it is possible to divide them into four groups.

1. Hotspots falling within the zone of direct impact of the Colliding Plates

The evolving mountain ridges, valleys and islands in the tectonically active hotspots where the plates meet are cradles of evolution of various groups of taxa and may remain so for many years to come. These include the hotspot areas of California floristic Province, Colombian Chaco, Western Ecuador, Central Chile, Eastern Himalaya, Philippines and New Caledonia recognized by Myers to which can be added Tropical Andes, Mesoamerican forests, Mediterranean Basin, Wallacea and New Zealand.

\section{Hotspots which fall just outside the zone of direct impact of} thecollidingplates

Though not falling within the range where the direct impact of the colliding plates is felt today, yet they are not far removed from such tectonically active areas. They are rich centres of biodiversity today but in course of time the evolution and richness of their biodiversity may depend, apart from other determining factors, on their moving towards or away from the centres of collision of the adjoining plates, of which they form a part. These include the uplands of Western Amazonia, Peninsular Malaysia and northern Borneo/Sundaland.

3. Hotspots which have indirectly been influenced by the plates in the recent past

The impacts of collision of the plates leading to the down warping and thrusting of one plate under the other are not only felt within the immediate vicinity of their points of contact but even on the distant opposite rims of the moving plates. Thus the movements which led to the rising of the Himalaya brought about the fracturing of the parts of the peninsula and marine subsidence of the fragments in the Arabian Sea giving rise to the scraps of 


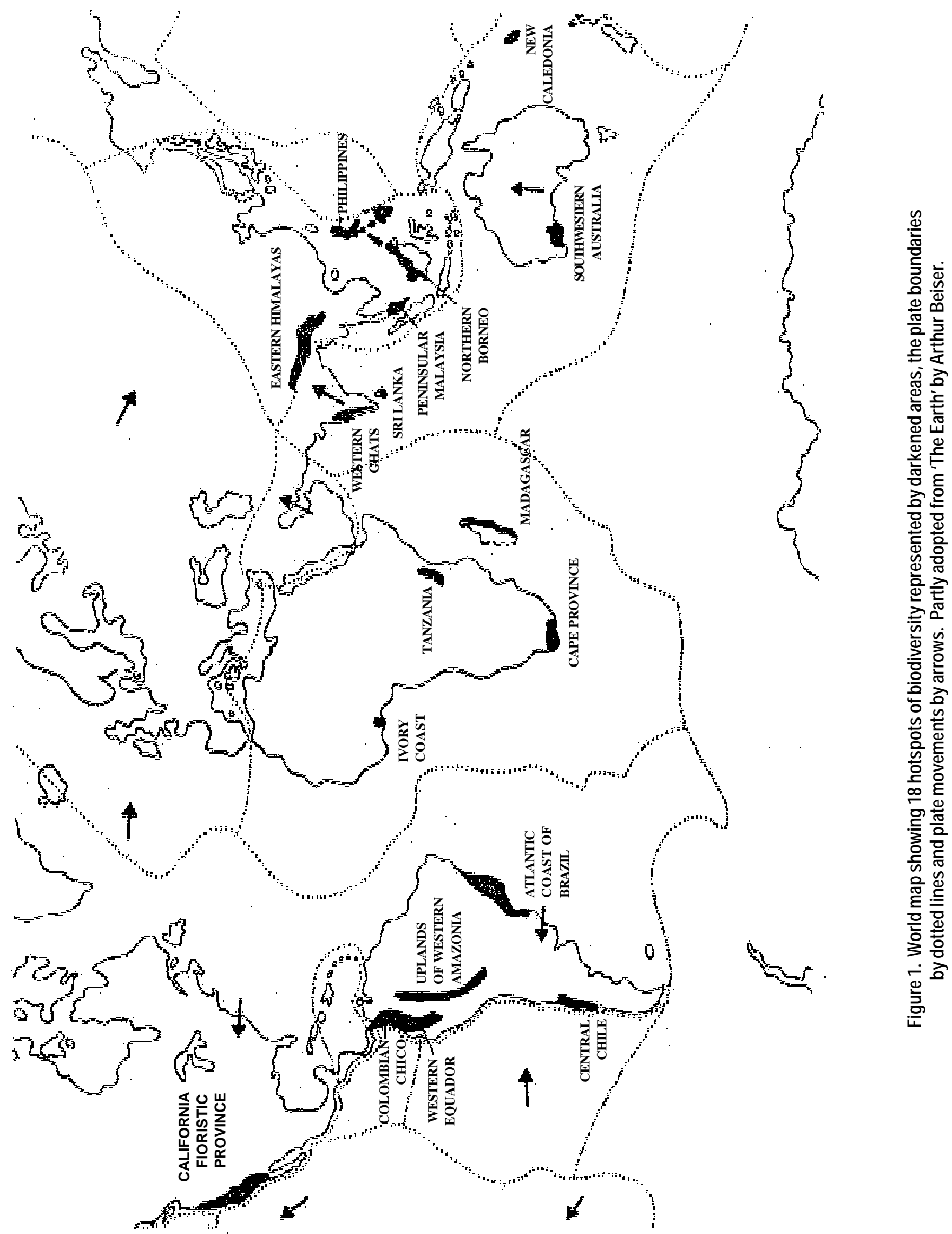


the Western Ghats and the hotspot areas of south-western Sri Lanka both of which constituted a single entity until the recent past (Mani, 1974). Similarly, the biodiversity of the hotspot areas of the Atlantic Coast of Brazil presumably have been indirectly influenced by the collision of the plates on the western and north-western borders of the continent. To this category also belongs the hotspot areas of Brazilian Cerrado and the Caribbean Islands.

4. Hotspots, the Biodiversity of which partly originated in unison during the remote past

As evidenced by geological history, the relict components of the general biodiversity found today in the hotspots of Atlantic coast of Brazil, Cape Province of Africa, Succulent Karoo and south-western Australia had a common origin before the three continents started drifting away. The commonly evolved original floras and faunas of these three hotspots were supplemented by those that evolved later. Similarly, today's relict components of Eastern are forests of Tanzania, Madagascar, Sri Lanka and the Western Ghats originated before these land masses got separated and their biodiversity evolved. Thus while 73 per cent of the 8600 species of plants found today in the floristic province of South Africa are endemics, in New Caledonia the floral endemicity is as high as 89 per cent (Wilson, 1992).

\section{Factors contributing to the development and evolution of Biodiversity of Hotspots}

Ecological systems are extraordinarily complex. Each species on earth is directly affected by diverse factors. Each single factor operates jointly with others in nature and the number of possible, indirect and interactive effects on each species is astronomical. If it is so, in respect of an individual species, the biodiversity of the hotspots of today or those that may evolve later is too complex to be determined or influenced by any set of factors. However, a few of the major contributing ones are given below.

Through geological times, continental land masses have changed in a way that enhances species formation. Around 100 million years ago the modern continents were in place and the water between them progressively widened. Modern floras and faunas evolved in a state of deepening isolation. Shallow seas spread and retreated creating new habitats and assemblages of organisms. The number of species of marine organisms have doubled and land plants have tripled in the last 100 million years (Wilson, 1992).

\section{Impacts of transform faulting}

The transform faulting produced by the geological process contributes substantially to the richness and evolution of the biodiversity of the hot spots. As the plates grind past one another, irregularities in their curving fault lines catch and snag, pushing up great folds on land. "When you push the mountains up something else has to go down" as Lindh (1998) puts it. Thus the valleys which often develop into some of the "hottest of the hot spots' are created. The high ground created by the fault system also forces the moist air arriving from the nearby oceans to rise, cool and deposit its load into the aquifers in the mountains. The valleys filled with young soil that has eroded from the surrounding hills bask in the sun and are supplied with plentiful water trapped by the mountains. No wonder the floras and the faunas of such areas are rich and often unique.

\section{Impact of mantle plumes}

Mantle plumes which are narrow, hot upwellings inside the earth constitute the volcanic 'hot spots' of geology. The arrival of a new plume head causes 'flood basalt' eruptions that spew millions of cubic kilometers of magma on to the earth's surface within a short geological period of a few million years. World wide, about a dozen of these giant eruptions are known to have occurred, in the past 250 million years. Such volcanic eruptions have affected continents and oceans and continue to do so. These also trigger or promote the rifting that radiates from the regions where they are found (Davies, 1998). The faunal diversity of Hawaii and other such areas have possibly been greatly influenced by the mantle plumes.

\section{Latitudinal diversity gradient}

The latitudinal diversity gradient, the increase in species (or any other taxonomic unit) encountered while travelling from the poles to the equator, provides a clue to the distribution of the biodiversity. A large part of the gradient is due to the richness of tropical rain forests. Thus 30 per cent of the world's bird species occur in the Amazon basin and another 16 per cent in Indonesia. Similarly, of the 250,000 species of vascular plants known, 68 per cent are found in the tropics and subtropics, especially in the rain forests (Wilson, 1992).

4. Impacts of solar energy, stable climate and larger area on biodiversity

The causes of tropical pre-eminance have been, to some extent, explained by the Energy Stability Area theory of Biodiversity or ESA theory for short, according to which more the solar energy, more stable the climate, and larger the area, greater is the diversity. Because animal and plant species of cold climates are adapted to a greater breadth of local environments, they also occupy larger geographical.ranges and are distributed across a wider range of latitudes. According to this trend, which has been called Rupoport's rule, as one travels from the colder temperate zones the ranges of individual species shrink steadily the closer one comes to the equator. Besides, the altitudinal range of species along the sides of mountains also contract (Wilson, 1992). Thus more species are packed into the same amount of space in the tropics than in the temperate zones.

\section{Survival in refugial pockets through the Ice Ages}

The tropical rain forests were not obliterated by the continental glaciers of the ice age. In the prolonged droughts that accompanied glacial cycles the lowland rain forests retreated and were replaced by grasslands and in a few places by semideserts. But there were refuges into which species assemblages could retreat. Each time the year-round rains came back, the forests expanded and hence have persisted over broad 
parts of the continents since their origin (Wilson, 1992).

6. Impacts of changes of topography, environmentand drainage systems

The Amazon basin harbours the most diverse assemblage of freshwater fishes in the world, including a disproportionately large number of marine-derived groups such as stingrays, flatfishes, puffer fishes and anchovies (Roberts, 1972). Lovejoy et al. (1998) opined that some freshwater fish species originated as a byproduct of movement of marine waters into the upper Amazon region during the early Miocene when South America experienced changes of topography, and river drainage patterns (Lundberg, in press).

Sea-level changes and tectonic loading of the foreland basin in the upper Amazon produced significant ingress of sea water, as indicated by the presence of marine and brackish molluscs, copepods and mangrove fossils (Horn, 1993). Nuttall (1990) says that the upper Amazon during the Miocene "offered intermittent connections with the Caribbean". These conditions would have been ideal for the isolation of marine fishes in desalinized habitats. A cross-section of the South American river fauna, including dolphins, appear to be derived from .marine ancestors. If these taxa originated contemporaneously with freshwater stingrays, the Miocene marine transgressions of South America will have had a profound effect on the structuring of five of the neotropical hot spots..

During most of its recent geological history, the African continent was cut off from Europe and Asia by the Tethys Sea. As the Tethys dwindled to its remnant as the Mediterranean Sea, Africa was joined to Europe and Asia. The obliteration of the Tethys Sea gave rise to the tertiary mountain areas known as eastern Tibet, Assam, Myanmar, South China and Indo-China and also established contact of the peninsula with Asia (Mani, 1974). The formation of the Assam gateway and the intrusion of the Mediterranean and tropical elements also contributed to the species richness of the hot spots of Asia and to some extent of Africa. Besides, the obliteration of the Tethys might have resulted in the derivation of some of the present day fauna of dolphins, fishes etc. of the northern Indian rivers from marine ancesters as has possibly happened in the case of some South American rivers.

\section{Conclusion}

Great biological diversity represented by hotspots takes long stretches of geological time to evolve. If a whale or a tiger represents a magnitude of evolution that comes along only rarely, how much more is it true of the hotspots with their assemblage of rare and diverse groups? Still if left undisturbed as in the geological past, new hotspots of biodiversity may emerge in the future as well. But the sixth great extinction spasm of geological time is already up on us, thanks to the demographic success of man. We owe it to ourselves and the generations to come not to allow any harm to visit the web of life in their centres of richness.

\section{Acknowledgement}

I am thankful to the Director, Zoological Survey of India, Calcutta for constant encouragement.

\section{Reference}

Cherian, P.T. (1996). On hotspots, warm spots and hot specks. Zoos' Print, 11(9): 9-11.

Conservation International (1990a). Biodiversity at risk. A preview of Conservation International's atlas for the 1990s. Conservation International, Washington, D.C.

Conservation International (1990b). The rainforest imperative. A ten-year strategy to save Earth's most threatened ecosystems. Conservation International, Washington, D.C.

Copley, J. (1998). Hotspots left to cool. New Scientist (2152): 25.

Davies, G. (1998). A channeled plume under Africa. Nature 395: 743744.

Groombridge, B. and J. Baillie (Eds.) (1996). The 1996 IUCN Red List of threatened animals. IUCN Publications Unit, Cambridge, United Kingdom.

Hoorn, C. (1993). Palaeogeogr. Palaeoclimato. Palaeoecol., 105 : 267-309. (Secondary reference from Nature, 1998, 396: 422).

Lindh, A. (1998). Give the fault its due. New Scientist 160 (2155): 42-44. Lovejoy, N.R., E. Bermingham and A.P. Martin (1998). Marine incursion into South America. Nature 396: 421-422.

Lundberg, J.G. (In press). Phylogeny and classification of Neotropical Fishes. L.R. Malabarba, R.E. Reis, R.P. Vari, C.A.S. Lucena \& Z.M.S. Lucena (Eds.) Museum de Ciencias e Tecnologia Porto Alegre, Brazil. Mani, M.S. (1974). Biogeographical evolution in India. In: Ecology and Biogeography of India. Ed. M.S. Mani Dr W. Junk Publishers, Hague PP. 1-707.

Mittermeier, R.A., N. Myers, J.B. Thomsen, G.A.B. da Fonesca and S. Olivieri (1998). Biodiversity hotspots and major tropical wilderness areas: Approaches to setting conservation priorities. Conservation Biology 12(3): 516-520.

Myers, N. (1988). Threatened biotas: Hotspots in tropical forests. The Environmentalist 8(3): 187-208.

Myers, N. (1990). The biodiversity challenge: expanded hotspots analysis. The Environmentalist 10(4): 243-256.

Nuttall, C.P. (1990). Bull. Br. Mus. Nat. Hist., 45: 165-371. (Secondary reference from Nature, 1998, 396: 422).

Olson, D.M. and E. Dinerstein (1997). The Global 2000: A representation approach to conserving Earth's distinctive ecoregions. World Wildlife Fund, Washington. D.C.

Roberts, T.R. (1972). Bull. Mus. Comp. Zool., 143: 117-147. (Secondary reference from Nature, 1998, 396: 422).

Stattersfield, A.J., M.J. Crosby, A.J. Long and D.C.Wege (1998). Endemic bird areas of the world: priorities for biodiversity conservation. BirdLife International, Cambridge, United Kingdom.

WWF and IUCN (1994). Centres of plant diversity: a guide and strategy for their conservation. Volume 1. Europe, Africa, South West Asia and the Middle East. IUCN Publications Unit, Cambridge, United Kingdom.

WWF and IUCN (1995). Centres of plant diversity: a guide and strategy for their conservation. Volume 2. Asia, Australia and the Pacific. IUCN Publications Unit, Cambridge, United Kingdom.

WWF and IUCN (1997). Centres of plant diversity: a guide and strategy $f$ or their conservation. Volume 3. The Americas. IUCN Publications Unit, Cambridge, United Kingdom.

Wilson, E.O. (1992). Diversity of Life. W.W.Norton \& Co. New York, $412 \mathrm{pp}$. 